\title{
In Vivo Modulation of Interacting Central Pattern Generators in Lobster Stomatogastric Ganglion: Influence of Feeding and Partial Pressure of Oxygen
}

\author{
Stefan Clemens, ${ }^{1}$ Jean-Charles Massabuau, ${ }^{2}$ Alexia Legeay, ${ }^{2}$ Pierre Meyrand, ${ }^{1}$ and John Simmers ${ }^{1}$ \\ ${ }^{1}$ Laboratoire de Neurobiologie des Réseaux Université de Bordeaux I and Centre National de la Recherche Scientifique, \\ Unité Mixte de Recherche 5816, F-33120 Arcachon, France, and 2Laboratoire d'Ecophysiologie et Ecotoxicologie des \\ Systèmes Aquatiques Université de Bordeaux I and Centre National de la Recherche Scientifique, Unité Mixte de \\ Recherche 5805, F-33120 Arcachon, France
}

The stomatogastric ganglion (STG) of the European lobster Homarus gammarus contains two rhythm-generating networks (the gastric and pyloric circuits) that in resting, unfed animals produce two distinct, yet strongly interacting, motor patterns. By using simultaneous EMG recordings from the gastric and pyloric muscles in vivo, we found that after feeding, the gastropyloric interaction disappears as the two networks express accelerated motor rhythms. The return to control levels of network activity occurs progressively over the following 1-2 d and is associated with a gradual reappearance of the gastropyloric interaction. In parallel with this change in network activity is an alteration of oxygen levels in the blood. In resting, unfed animals, arterial partial pressure of oxygen $\left(\mathrm{PO}_{2}\right)$ is most often between 1 and $2 \mathrm{kPa}$ and then doubles within $1 \mathrm{hr}$ after feeding, before returning to control values some $24 \mathrm{hr}$ later. In vivo, experimental prevention of the arterial $\mathrm{PO}_{2}$ increase after feeding leads to a slowing of pyloric rhythmicity toward control values and a reappearance of the gastropyloric interaction, without apparent effect on gastric network operation. Using in vitro preparations of the stomatogastric nervous system and by changing oxygen levels uniquely at the level of the STG within the range observed in the intact animal, we were able to mimic most of the effects observed in vivo. Our data indicate that the gastropyloric interaction appears only during a "free run" mode of foregut activity and that the coordinated operation of multiple neural networks may be modulated by local changes in oxygenation.

Key words: lobster; feeding behavior; stomatogastric ganglion; neural network; synaptic interaction; oxygen; hypoxia; modulation; internetwork coordination
Apart from the question of how neural networks are constructed intrinsically in terms of synaptic wiring and cellular membrane properties, a large amount of work has been devoted to understanding the functional capabilities of networks under extrinsic neuromodulatory instruction (Steriade et al., 1993; Grillner et al., 1995; Marder and Calabrese, 1996). Neuromodulatory transmitters and hormones are able to alter membrane properties and synaptic efficacy of neurons in a functional network, thereby reshaping its pattern of activity (Harris-Warrick et al., 1992; McCormick and Bal, 1994; Katz, 1995; Katz and Frost, 1995a,b). However, although neuromodulatory processes are now relatively well understood, even at the single cell level (Kaczmarek and Levitan, 1987), their precise physiological relevance in situ to the generation of behavior is still largely unknown.

In this respect, a useful model is the crustacean stomatogastric nervous system (STNS), which drives rhythmic activity of the muscles producing foregut movements. This system includes several spontaneously active networks that can be studied both in

Received Oct. 24, 1997; revised Jan. 14, 1998; accepted Jan. 20, 1998.

S.C. was supported by two predoctoral grants (ERBCHBICT 930509 and ERBFMBICT 960693) under the auspices of the 3rd and 4th Framework program of the European Union, "Human Capital and Mobility" and "Training and Mobility of Researchers," respectively. A.L. held a grant by the French Ministry of Research and Education (MESR). This work also benefitted from a Human Frontier Science Program grant.

Correspondence should be addressed to John Simmers, Laboratoire de Neurobiologie des Réseaux Université de Bordeaux I and Centre National de la Recherche Scientifique, Unité Mixte de Recherche 5816, Place de Dr. Peyneau, F-33120 Arcachon, France.

Copyright (C) 1998 Society for Neuroscience $0270-6474 / 98 / 182788-12 \$ 05.00 / 0$ vitro (Selverston and Moulins, 1987; Harris-Warrick et al., 1992) and in vivo (Rezer and Moulins, 1983, 1992; Heinzel et al., 1993). The best studied of these are the gastric and pyloric neural circuits located in the stomatogastric ganglion (STG) that generate masticatory movements of the gastric mill and filtering contractions of the pyloric chamber. Substantial data have demonstrated an ability of these networks to express a wide range of operational variants in vitro, and a number of modulatory neurotransmitters and hormones influencing these circuits have been identified (for review, see Selverston and Moulins, 1987; HarrisWarrick et al., 1992). Moreover, a recent in vitro study has suggested that local partial pressure of oxygen $\left(\mathrm{PO}_{2}\right)$ at the STG level can also influence pyloric activity in a neuromodulatory-like manner (Massabuau and Meyrand, 1996). Specifically, changes in oxygen levels were proposed to exert a regulatory effect on pyloric network function by modulating cycle frequency and phase relationships via a specific action on a single neuron of the circuit.

Recently, Clemens et al. $(1996,1998)$ reported that in vivo the STG networks of the European lobster Homarus gammarus are almost continuously active in the resting and unfed animal and that they express a strict coordinating interaction via specific neurons of each network. Thus, the first aim of the present study was to examine the changes in pyloric and gastric network behavior and their interaction in vivo when working conjointly after feeding activity. In a second step, we wished to assess whether circulating oxygen contributed to the expression of feedingrelated changes, in a manner commensurate with a direct modulatory role. Our data demonstrate that feeding causes long-lasting 
modulation of pyloric and gastric network activity and that the evolution of arterial $\mathrm{PO}_{2}$ follows a similar time course. Moreover, we show that the pyloric network frequency and the efficacy of the cross-circuit interaction can be manipulated experimentally both in vivo and in vitro by different physiological levels of $\mathrm{PO}_{2}$. Our results suggest that oxygen can modulate the expression of oscillating neural networks and their interconnecting synaptic pathways.

\section{MATERIALS AND METHODS}

The study was performed on adult European rock lobsters, H. gammarus, (400-600 gm) of either sex and in the intermolt stage (stage C3 and D1) (Aiken, 1973), purchased from local commercial suppliers (AiguillonMarée, Arcachon, France). Before the experiments, animals were maintained for at least 1 week in 5001 tanks of running, aerated (i.e., normoxic) seawater (salinity 29-32\%). During maintenance and experimental periods, the temperature was kept at $16 \pm 1^{\circ} \mathrm{C}$. Three types of experiment were performed: in vivo electromyographic (EMG) recordings before and after feeding in normoxic and hypoxic waters, in vivo arterial $\mathrm{PO}_{2}$ measurements before and after feeding in normoxic and hypoxic waters, and in vitro extracellular recordings in salines equilibrated at various low and physiological levels of oxygenation.

Electromyographic recording before and after feeding in normoxic and hypoxic waters. The EMG recording methods are as described previously in detail (Clemens et al., 1998). Briefly, animals were immobilized with the dorsal carapace above the water line, and Teflon-insulated silver wire electrodes (core diameter of $125 \mu \mathrm{m}$; A-M Systems Inc.) were implanted in the appropriate muscles from the dorsal aspect of the cephalothorax, near the midline. They were connected to highly flexible wires (diameter, $1 \mathrm{~mm}$ ) and fixed to the carapace with dental cement (Durelon, ESPE). After electrode implantations, animals were kept under dim light conditions in isolated 501 tanks equipped with a "natural" environment in which they could move freely, dig, and hide. They could not see the experimenter. The free ends of the electrodes were connected to amplifiers (GRASS P5 AC-preamplifier), and data were displayed on a Tektronix 5113 oscilloscope, stored on a Schlumberger tape recorder (ENERTEC S.A.), and simultaneously recorded on a Gould TA 11 electrostatic chart recorder.

Experiments consisted of feeding the lobsters (previously unfed for $3-7 \mathrm{~d})$ with pieces $(\sim 5-10 \mathrm{gm})$ of intermolt crab and recording the motor expression of the gastric and pyloric networks before and after food intake in normoxic, air-equilibrated waters $\left(\mathrm{PO}_{2}=21 \mathrm{kPa}\right.$, corresponding to an $\mathrm{O}_{2}$ fraction $\left(\mathrm{Fo}_{2}\right)$ of $\left.21 \%\right)$ and hypoxic waters $\left(\mathrm{PO}_{2}=4 \mathrm{kPa} ; \mathrm{Fo}_{2}=\right.$ $4 \%$ ), respectively. EMG electrodes were implanted during the 3-7 $\mathrm{d}$ unfed interval, and animals were left to recover for at least $1-2 \mathrm{~d}$ before recordings started. In the series of experiments under hypoxic conditions, a calibrated electrode of an oxygen meter (YSI Model 57, Yellow Spring Instruments) was placed in the tank and water $\mathrm{PO}_{2}$ was monitored continuously. Animals $(n=5)$ were fed $4-6 \mathrm{hr}$ later $\left(t_{0}\right)$. Then at $t_{0}+1$ $\mathrm{hr}$, a transient hypoxic exposure was imposed that lasted 2-3 hr. Electromyographic recordings were made throughout, along with a monitor of changes in water $\mathrm{PO}_{2}$. Within 60-80 min, the inspired $\mathrm{PO}_{2}$ in the water decreased to $4 \mathrm{kPa}$, a value at which oxidative metabolism of the lobster is not yet impaired (McMahon and Wilkens, 1975). Recovery toward control conditions was obtained within $45 \mathrm{~min}$ by bubbling air. After experiments, animals were anesthetized on ice, and the electrodes were connected in turn to an AC-current source that injected $500 \mathrm{~mA}$ for 0.5 sec to tag the recorded muscle with a black spot. This procedure allowed muscle identification during subsequent autopsy.

Arterial $\mathrm{PO}_{2}$ measurements before and after feeding. Analyses were performed on 17 lobsters of either sex that were kept in 351 tanks with running seawater renewed at a rate of $0.51 / \mathrm{min}$. The conditions in the tanks were as follows: inspired $\mathrm{PO}_{2}=20-21 \mathrm{kPa}$; inspired $\mathrm{PCO}_{2}=0.1$ $\mathrm{kPa}, \mathrm{pH} 7.8-7.9$, depending on the titration alkalinity, which was $1.8-2.0$ $\mathrm{mEq} / 1$. Hypoxic water was obtained by bubbling a $\mathrm{N}_{2} /$ air gas mixture via mass flow controllers (model FC-260, Tylan General) driven by a laboratory-constructed programmable control unit. For arterial blood sampling by heart puncture, animals were prepared $2-3 \mathrm{~d}$ before the experiments. A hole was drilled through the carapace above the heart. The underlying epidermis was left intact, and a small piece of rubber was glued over the hole to prevent blood loss. The experiments were performed in two series. The first one, under normoxic conditions at water $\mathrm{PO}_{2}=20-21 \mathrm{kPa}$, consisted of (1) sampling an animal after a period of
$7 \mathrm{~d}$ without feeding; (2) feeding the animal the following day $\left(t_{0}\right)$ with a halved crab ( $\sim 5-10$ gm, without claws and legs); and (3) repeating blood sampling from the same individual at $t=t_{0}+2,+5$, and $+30 \mathrm{hr}$. In the second series, blood sampling at $t_{0}+2 \mathrm{hr}$ was performed in water maintained hypoxic (inspired $\mathrm{PO}_{2}=4 \mathrm{kPa}$ ) from $t_{0}+1$ to $+3 \mathrm{hr}$. At each sampling, arterial blood was obtained in $<20 \mathrm{sec}$ by gently removing an individual from the water and puncturing its heart via the rubber membrane with a capillary glass tube attached to a syringe needle. With this technique, the blood sample (a volume of $100 \mu \mathrm{l}$ ) is driven into the glass tube by the beating heart. Arterial $\mathrm{PO}_{2}$ was determined within 3 min of sampling with an E5046 Radiometer polarographic electrode with thermostat set at seawater temperature. As critically assessed in Forgue et al. (1992) and Massabuau and Forgue (1996), this sampling technique, developed in both laboratory and field conditions, is considered to provide true in vivo blood $\mathrm{PO}_{2}$ values in crustaceans.

In vitro extracellular recordings in salines equilibrated at different physiological levels of oxygenation. Experiments were performed on 14 preparations. The stomatogastric nervous system (STNS) was dissected according to Selverston and Moulins (1987). For this the anterior paired commissural ganglia $(\mathrm{CoG})$, the esophageal ganglion, and their interconnecting nerves were left attached to the stomatogastric ganglion (see Fig. $1 A)$, and the isolated system was placed in an experimental set-up described previously by Massabuau and Meyrand (1996). In short, the STG, commissural ganglion, and commissural connectives were desheathed, and the preparation was pinned down in a Sylgard-lined petri dish. The entire preparation was superfused with air-equilibrated saline, except the STG, which was pinned onto a separate Sylgard plate $(10 \times 6 \times 2 \mathrm{~mm})$ and enclosed in a $300 \mu \mathrm{l}$ glass chamber (internal size, $10 \times 6 \times 5 \mathrm{~mm})$ used as an artificial artery to allow for separate superfusion at different physiological $\mathrm{PO}_{2}$ (see Fig. $1 \mathrm{~A}$ ). The chamber was gravity-fed with saline at a constant flow $(3-4 \mathrm{ml} / \mathrm{min}$ ), and the thermostat was set at $15 \pm 0.2^{\circ} \mathrm{C}$ for the entire preparation by means of a laboratory-constructed thermoelectric device. Extracellular nerve recordings were made with monopolar platinum electrodes insulated from the bath with Vaseline and connected to laboratory-constructed extracellular amplifiers. Data were displayed on a Tektronix 5113 oscilloscope, recorded on a Gould ES 1000 electrostatic chart recorder, and stored on videotape coupled to a Neurocorder DR 890.

The physiological saline used for the superfusion was composed of (in mM): $\mathrm{NaCl} 479, \mathrm{KCl} 13.2, \mathrm{CaCl}_{2} 13.7, \mathrm{MgSO}_{4} 10, \mathrm{Na}_{2} \mathrm{SO}_{4} 3.9, \mathrm{HEPES}$ 5. The $\mathrm{pH}$ was adjusted to 7.45 with $\mathrm{HCl}$. The low $\mathrm{PO}_{2}$ gas mixtures were obtained by mixing $\mathrm{N}_{2} / \mathrm{O}_{2} / \mathrm{CO}_{2}$ as described above and in Massabuau and Meyrand (1996). During experiments, $\mathrm{PO}_{2}$ was varied in the range of 1-5 kPa, and the $\mathrm{CO}_{2}$ partial pressure was maintained at $0.4 \mathrm{kPa}$, a typical value in blood of water-breathers (Rahn, 1966). Between experiments, the gas phase composition was analyzed using a paramagnetic $\mathrm{O}_{2}$ analyzer (Servomex 1100A) and an infrared $\mathrm{CO}_{2}$ analyzer (Servomex $1410 \mathrm{~B})$ calibrated with high grade $\mathrm{N}_{2}$ and precision gas mixtures $\left(\mathrm{FO}_{2}=\right.$ $\left.3.99 \pm 0.04 \% ; \mathrm{FCO}_{2}=1.01 \pm 0.01 \%\right)$. The $\mathrm{O}_{2}$ concentration $\left(\mathrm{Co}_{2}\right)$ in the saline was calculated according to Henry's law $\left(\mathrm{Co}_{2}=\alpha \mathrm{O}_{2} \cdot \mathrm{PO}_{2}\right)$ with $\alpha \mathrm{O}_{2}=12.4 \mu \mathrm{mol} / 1 \cdot \mathrm{kPa}$ at $14^{\circ} \mathrm{C}$.

Data analysis. After the experiments, data were digitized with a CED 1401 plus-interface (CED, Cambridge, England) and stored on an IBM-PC equipped with an external magneto-optical disk. Quantitative analyses of extracellular recordings were used to describe and compare the activity patterns, including cycle period and burst duration, of the stomatogastric muscles under the different experimental conditions. Data analysis was performed by using the Spike2-program package (CED) and adjusting the algorithms submitted to the experimental conditions. In a subsequent analysis, SigmaPlot and SigmaStat (Jandel Scientific, San Rafael, CA) were used for mathematical calculations and comparisons of data. Data are reported as mean \pm SE except where stated otherwise. Differences were evaluated using paired $t$ test or nonparametric MannWhitney and Kolmogorov-Smirnov tests, and $p<0.05$ was set as the limit of significant difference between samples.

\section{RESULTS}

\section{Performance and interactions of the gastric and pyloric networks in unfed animals}

Under resting conditions in vivo (animals unfed), the pyloric and gastric networks (consisting of 12 and 16 neurons, respectively) are almost continuously active and coordinated via a direct inhibitory synapse (Fig. 1B) (Clemens et al., 1998). It is important 
A superior
ganglia artificial glass artery motor nerves
B

Pyloric network Gastric network

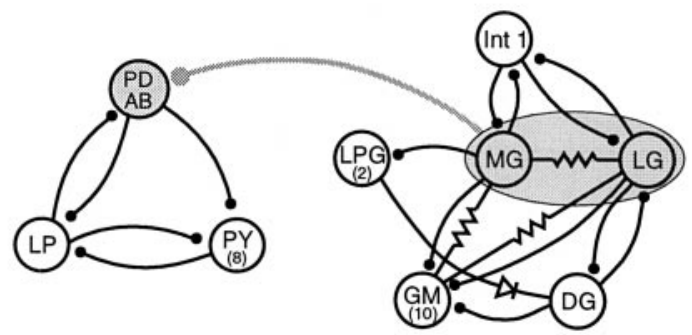

C

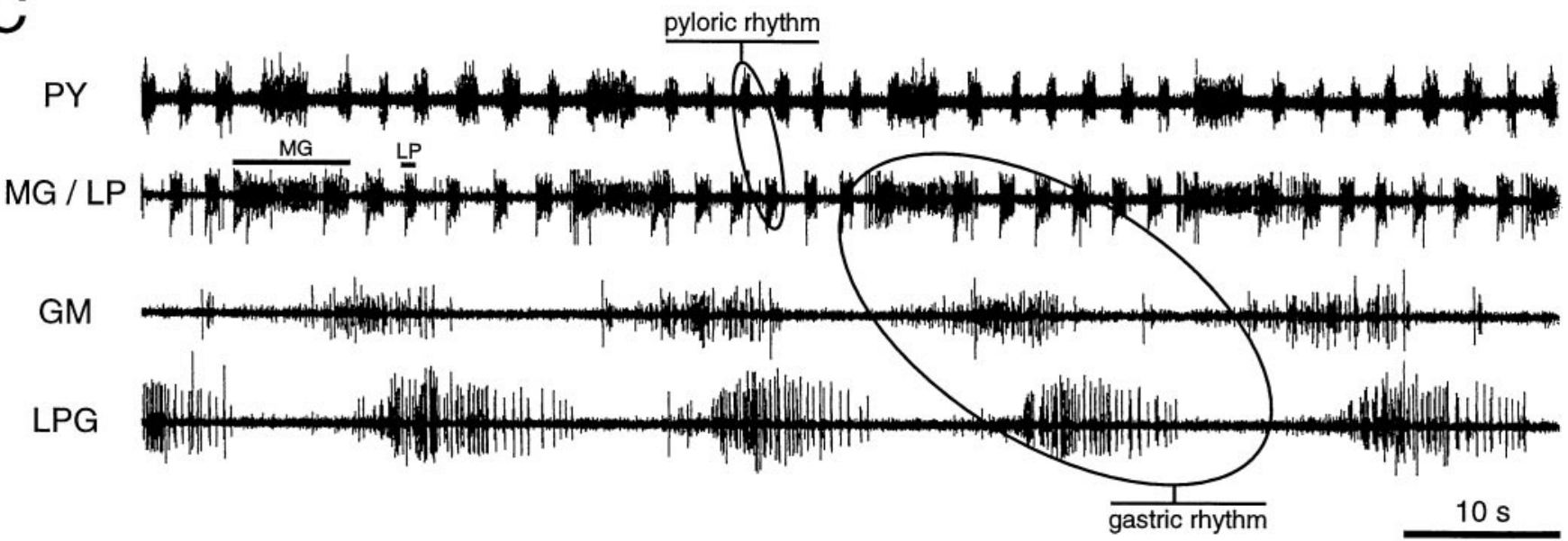

Figure 1. Stomatogastric nervous system (STNS) of the European lobster H. gammarus. A, The dissected STNS in vitro. The stomatogastric ganglion $(S T G)$ receives descending input from the brain and other STNS ganglia via the single stomatogastric nerve (stn). For in vitro experiments, the STG was placed in an artificial glass artery to permit oxygenation changes at the level of the ganglion only. $B$, Synaptic wiring diagram of the pyloric and gastric networks. The pyloric network consists of 11 motor neurons and 1 interneuron $(A B)$, and the gastric circuit is composed of 15 motor neurons and 1 interneuron (Int 1). An inhibitory synapse between the gastric neurons $M G / L G$ and the pyloric pacemaker group $P D / A B$ mediates an internetwork connection. Stick and ball symbols denote chemical inhibitory synapses, resistor symbols represent electrical connections, and diode indicates rectifying electrical coupling. $C$, Spontaneous activity of pyloric and gastric circuits in vivo. Simultaneous recording of the pyloric muscles innervated by LP neuron and PY neurons ( pyloric rhythm) and of three gastric muscles innervated by MG neurons, GM neurons, and LPG neurons, respectively ( gastric rhythm). Note that after the onset of each MG neuron burst the following PY neuron burst is substantially prolonged, which is caused by the inhibitory interaction between the gastric and pyloric networks. $C o G$, Commissural ganglion; $O G$, esophageal ganglion; lvn, lateroventricular nerve; $m v n$, medioventricular nerve; $P D$, pyloric dilator; $A B$, anterior burster; $L P$, lateral pyloric constrictor; $P Y$, pyloric constrictor; Int 1 , interneuron $1 ; L P G$, lateral posterior gastric; $M G$, medial gastric; $L G$, lateral gastric; $G M$, gastric mill; $D G$; dorsal gastric.

to note that because the motor neurons themselves form the central pattern generators responsible for the gastric and pyloric rhythms, electromyographic recordings provide a direct image of ongoing central network activity within the STG. The pyloric network, represented in Figure $1 C$ by recordings from the constrictor muscles $\mathrm{c} 1$ and $\mathrm{c} 2$, which are driven by the single lateral pyloric (LP) motor neuron and eight pyloric (PY) motor neurons, respectively, expresses a continuous activity with a mean cycle period of $2.5 \pm 0.2 \mathrm{sec}(n=25)$ and mean burst durations of $0.9 \pm$ $0.1 \mathrm{sec}(\mathrm{LP})$ and $1.0 \pm 0.2 \mathrm{sec}(\mathrm{PY})$. The gastric mill, as monitored in Figure $1 C$ from the power stroke muscles of the lateral teeth [innervated by the unique medial gastric (MG) neuron] and the medial tooth [innervated by the gastric mill (GM) neurons], as well as from the return stroke muscle of the lateral teeth [innervated by the two lateral posterior gastric (LPG) neurons], is also rhythmically active, with mean cycle periods of $20-40 \mathrm{sec}$, depending on the animal. After onset of each burst in the gastric MG neuron, the following pyloric period is prolonged consider- ably (Fig. $1 C, P Y$ trace). This prolongation is attributable to a direct inhibitory effect of the medial gastric/lateral gastric (MG/ LG) neurons onto the pyloric pacemaker neurons [pyloric dilator/ anterior burster (PD/AB)] (Fig. 1B), which in turn allows the PY neurons to continue firing for longer in the next pyloric cycle (Fig. 1C) (Clemens et al., 1998). These coordinated patterns of activity are very stable and show virtually no change for weeks if the animal remains unfed.

\section{Influence of feeding on the expression of the gastric and pyloric networks}

To observe the stomatogastric networks under feeding-related working conditions, animals were fed (see Materials and Methods), and the corresponding changes in the network activities were followed during the ensuing days. Figure $2 A$ illustrates one such experiment. Before feeding (Fig. $2 A_{1}$ ), both networks were active at their different inherent frequencies and expressed an intercircuit interaction as described above. Thus gastric MG 

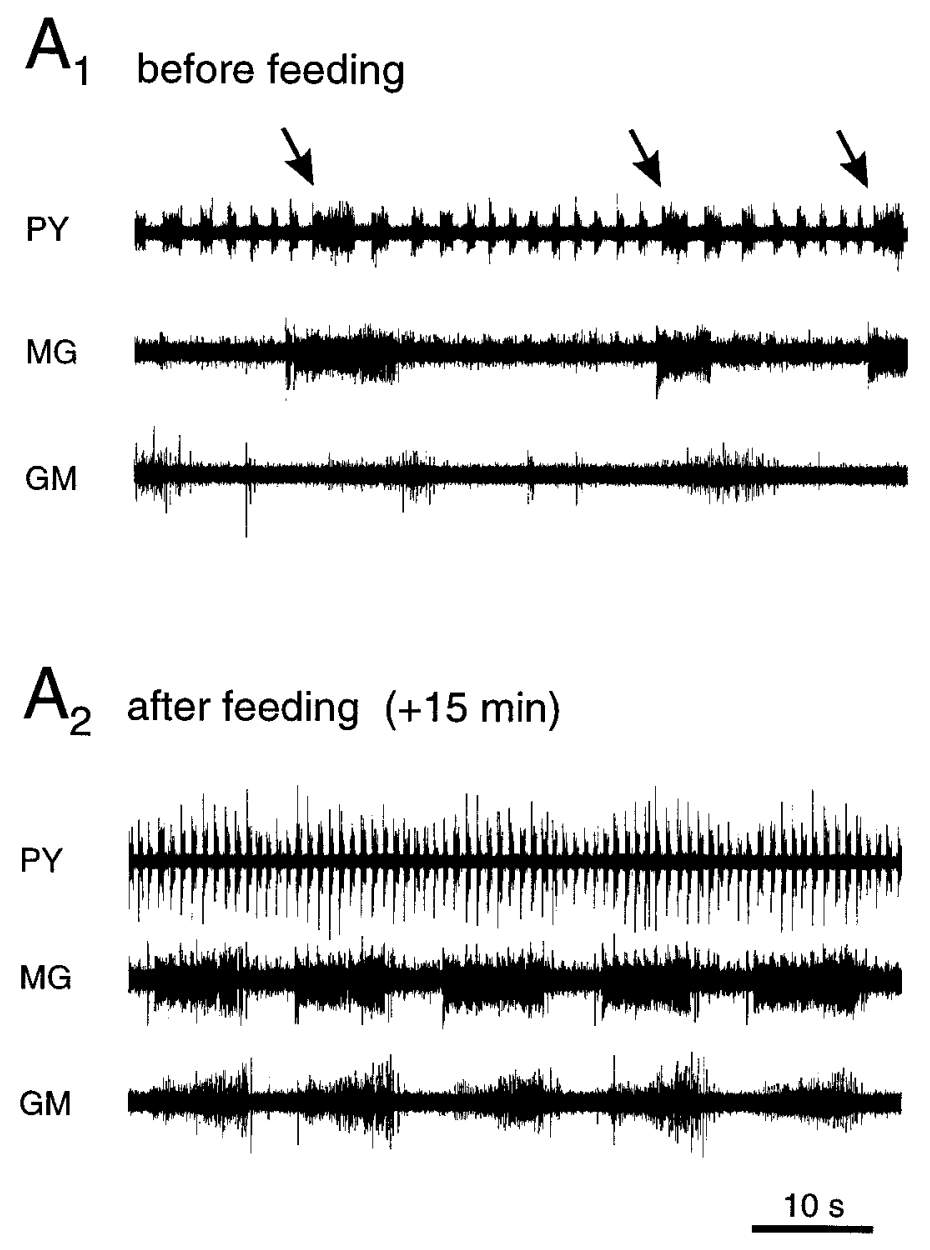
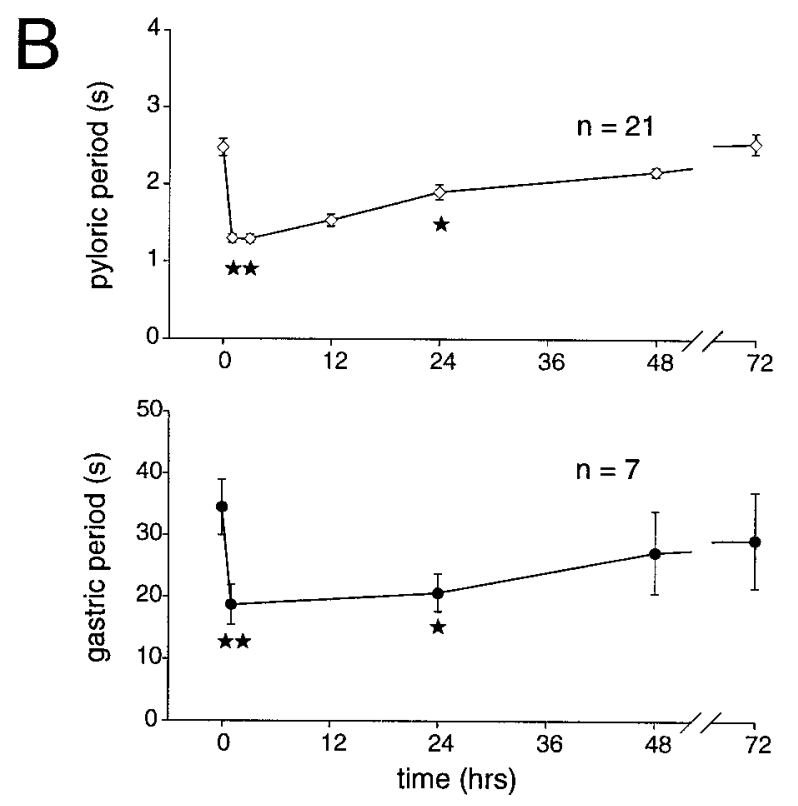

C

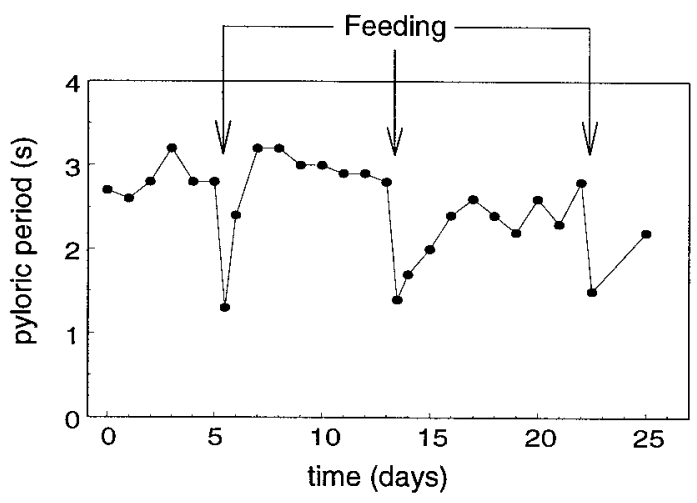

Figure 2. Effects of feeding on motor expression of the STG networks. $A_{1}$, EMG recordings from pyloric (innervated by PY neurons) and gastric muscles (innervated by MG and GM neurons) before feeding. Pyloric and gastric networks oscillate at periods of $2.5 \mathrm{sec}$ and $30-40 \mathrm{sec}$, respectively. Note PY neuron burst prolongation after onset of each MG neuron burst (arrows). $A_{2}$, EMG recordings from the same animal after feeding. Both networks oscillate at higher frequencies, and the gastropyloric interaction is no longer evident. Note that the fraction of each gastric cycle during which MG and GM neurons are active is increased considerably. $B$, Pooled data showing the effects of feeding on pyloric (top) and gastric (bottom) network activity. Each point is the mean period \pm SE of 5 min samples. Significant differences in motor expression persist for at least 24 hr after ingestion. ** $p<0.01$; ${ }^{*} p<0.05$; Mann-Whitney test. $C$, Repetitive feeding (arrows) elicits reproducible accelerations of pyloric activity in a single animal during a 4 week recording period. Each feeding stimulus accelerates pyloric activity by $\sim 50 \%$, albeit with varying recovery slopes.

neuron firing is associated with a longer pyloric PY neuron burst (see arrows). After feeding (Fig. $2 A_{2}$ ), both networks expressed strongly accelerated activity patterns; pyloric periods dropped from a mean value at rest of $2.5 \mathrm{sec}$ to $\sim 1.4 \mathrm{sec}$, and gastric periods decreased from $40 \mathrm{sec}$ to $\sim 15 \mathrm{sec}$. Importantly, moreover, the interaction between the two networks disappeared completely. This change in network activity is sudden and is closely associated with a preceding food uptake. We did not observe any particular transition pattern during the actual expression of ingestion behavior (not shown).

These dramatic changes in the activities of gastric and pyloric networks are not only restricted to periods of actual feeding behavior. As is shown in Figure $2 B$, the motor patterns of pyloric and gastric networks after feeding recover progressively and in parallel, with significant differences in cycle period between control and test samples after feeding that last for $24-48 \mathrm{hr}$. However, the slope of this recovery and the resting values obtained may differ considerably from animal to animal and within single individuals. This variability is seen in Figure $2 C$, where a single animal was monitored during the course of three feeding sessions over a period of 4 weeks. Each feeding elicited a sudden acceleration of pyloric activity that returned toward control values between 2 and $4 \mathrm{~d}$ afterward. Note also that the fraction of the gastric cycle during which $\mathrm{MG}$ and GM neurons are active is considerably increased after feeding (compare Fig. $2 A_{1}$ and $2 A_{2}$ ), whereas the corresponding duty cycle for the LPG neurons decreases (see below).

Significantly, the gastropyloric interaction that disappeared with the expression of the feeding motor patterns also reappears with the gradual slowing of the pyloric and gastric rhythms. Figure $3 A$ illustrates a typical experiment in which changes of LP and PY neuron burst duration after feeding, as well as the pyloric period, are plotted. LP neuron bursts decreased from $0.8 \pm 0.1 \mathrm{sec}$ to $0.3 \pm 0.1 \mathrm{sec}$, whereas PY 
A
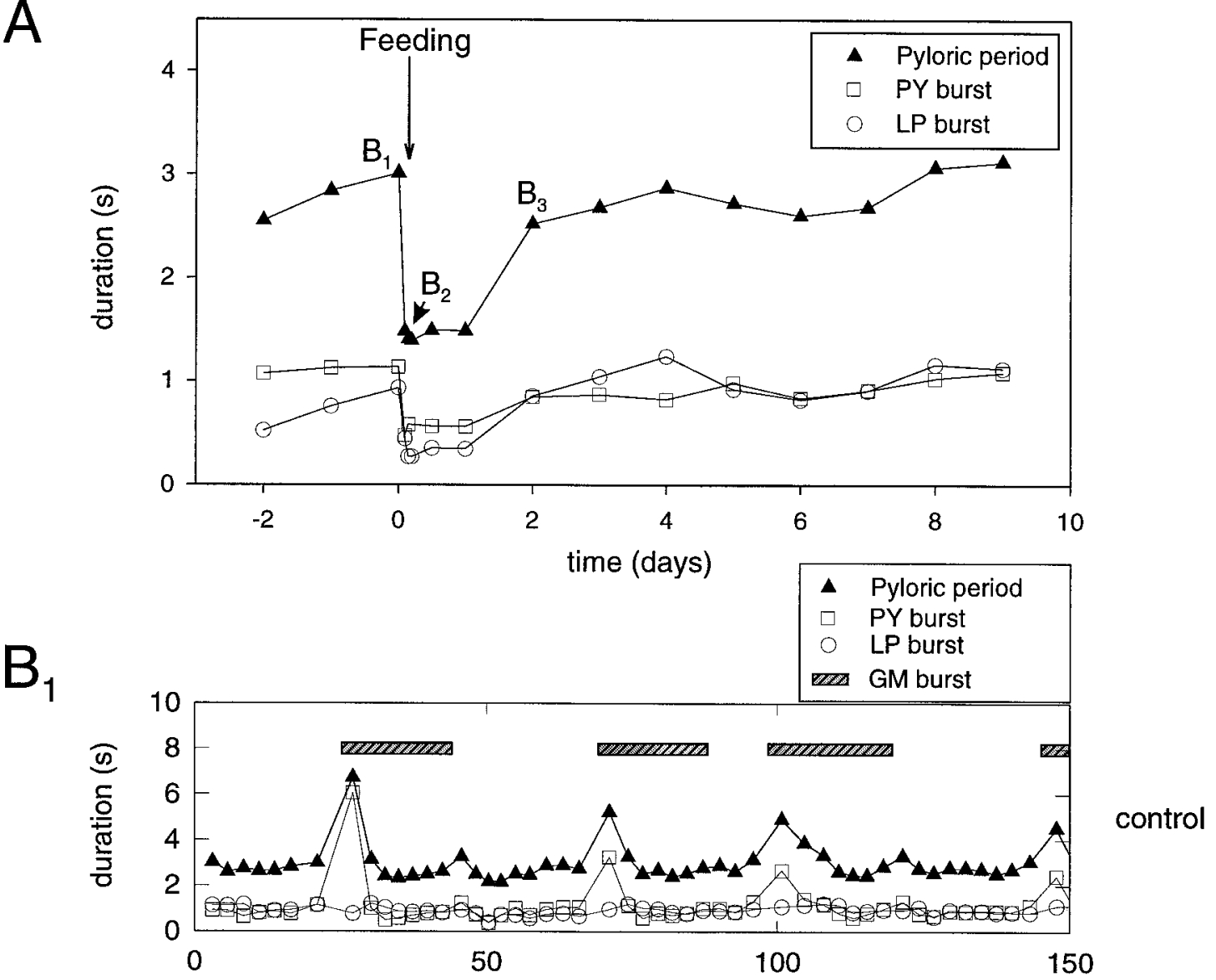

$\mathrm{B}_{2}$

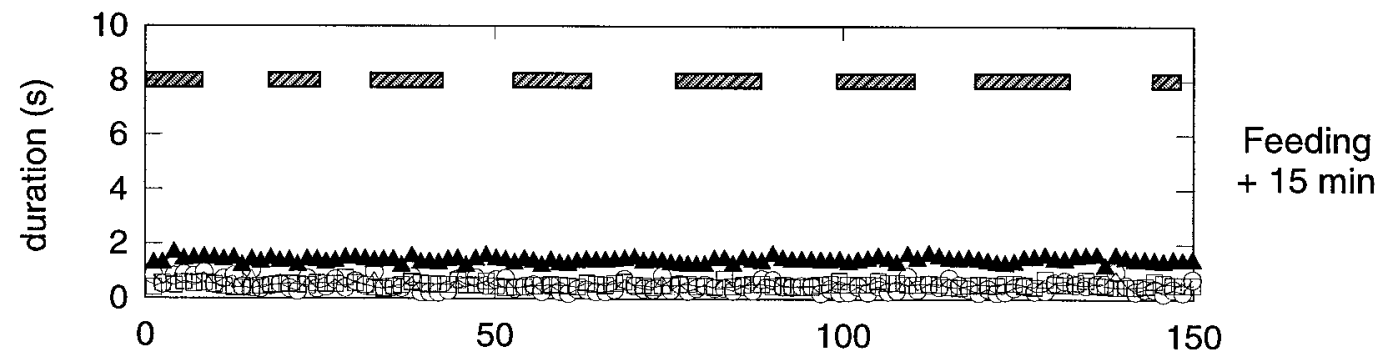

$\mathrm{B}_{3}$

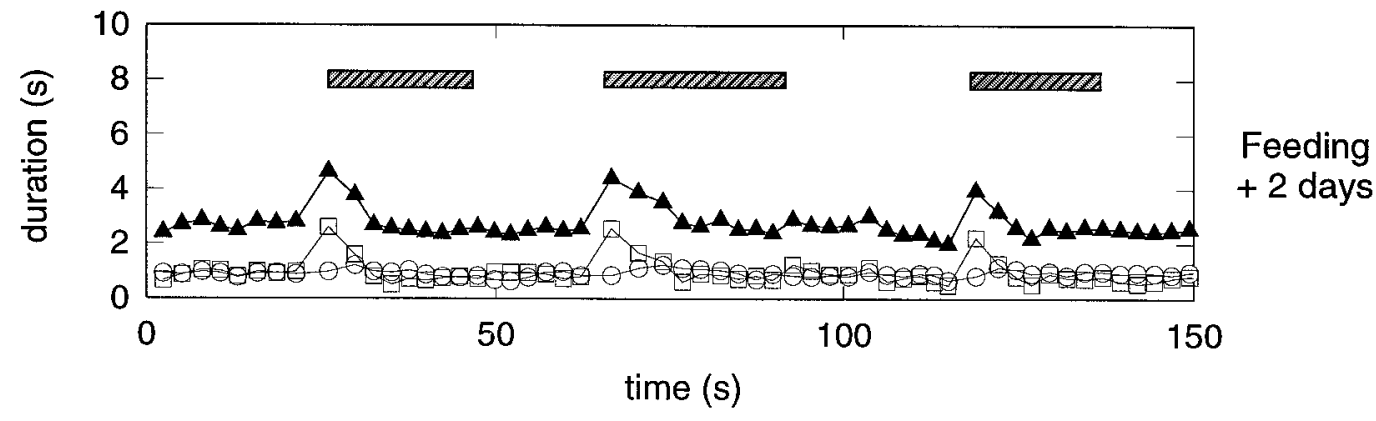

Figure 3. Evolution of pyloric activity and gastropyloric interaction after feeding. $A$, Typical time courses of mean pyloric periods and LP and PY neuron burst duration after feeding. All three parameters are reduced abruptly and then recover gradually over the ensuing $2 \mathrm{~d}$. $B$, Cycle-by-cycle analysis of EMG samples in the same experiment before feeding $\left(B_{1}\right), 15$ min after feeding $\left(B_{2}\right)$, and $2 \mathrm{~d}$ after feeding $\left(B_{3}\right)$. $B_{1}$, Before feeding, pyloric periods (black triangles) are transiently prolonged after the onset of each recorded GM neuron burst (see bar). This is associated with a considerable prolongation of PY neuron (square symbol) burst duration only. $B_{2}$, Fifteen minutes after feeding, both networks oscillate at higher frequencies, LP neuron (open circle) and PY neuron burst durations decrease, and the pyloric perturbation has completely vanished. $B_{3}$, Two days after feeding, the rhythmic gastropyloric interaction reappears as the activity of the two networks returns toward control values. 

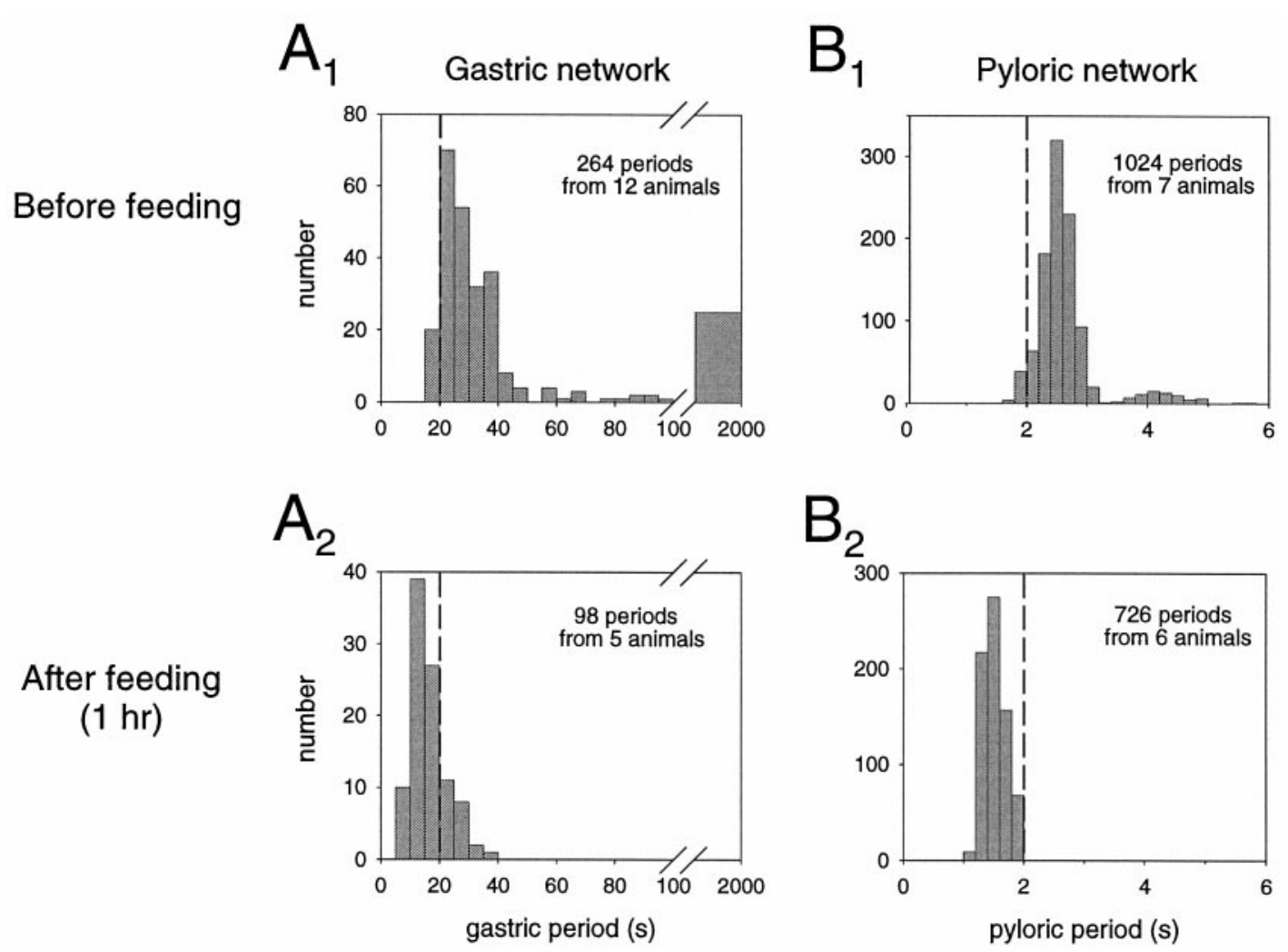

$\mathrm{B}_{2 \mathrm{son}}$

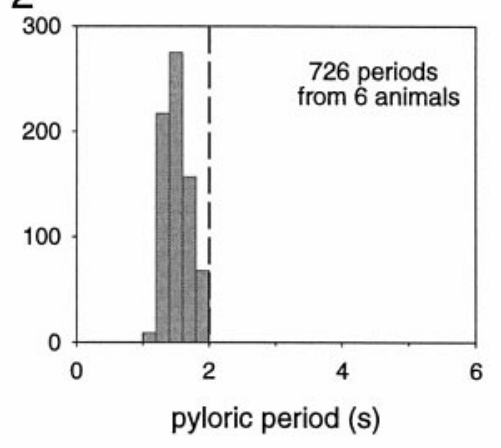

Figure 4. Distribution histograms of gastric and pyloric periods before and after feeding. $A$, Gastric network. $A_{1}$, Before feeding, gastric periods are widely varied, mostly occurring between 20 and $40 \mathrm{sec}$. Note that periods $>100 \mathrm{sec}$ were considered as pauses. $A_{2}$, After feeding, gastric periods decreased to $10-20 \mathrm{sec}$ without pauses. $B$, Pyloric circuit. $B_{1}$, Before feeding, pyloric periods display a bimodal distribution at $2.4-2.8 \mathrm{sec}$ and at $3.8-4.4 \mathrm{sec}$. The latter mode corresponds to the rhythmic perturbations by gastric activity. $B_{2}$, After feeding, the second mode disappears with pyloric periods now occurring mostly between 1.4 and $1.8 \mathrm{sec}$.

neuron bursts decreased from $0.9 \mathrm{sec} \pm 0.3 \mathrm{sec}$ to $0.5 \pm 0.1 \mathrm{sec}$ $(n=19)$.

The three panels in Figure $3 B$ show a cycle-by-cycle analysis of the gastric and pyloric activity in the same animal just before feeding (Fig. $\left.3 B_{1}\right)$ and $15 \mathrm{~min}\left(3 B_{2}\right)$ and $2 \mathrm{~d}$ after feeding $\left(3 B_{3}\right)$. Before feeding (Fig. $3 B_{1}$ ), the gastric and pyloric networks are active and express a strong interaction. As seen previously, each onset of a gastric timed burst is accompanied by a transient perturbation of the pyloric network that manifests itself by a prolonged PY neuron burst, but with no LP neuron burst alteration. Fifteen minutes after feeding (Fig. $3 B_{2}$ ), both networks operate at considerably higher frequencies and no longer express any temporal interaction. Thus the gastric and pyloric networks have become decoupled and oscillate completely independently. It is not until 12-24 hr after feeding that the gastropyloric interaction starts to reappear, and it takes an additional 1-2 d (Fig. $3 B_{3}$ ) to return to control status.

The distribution patterns of gastric and pyloric periods before and after feeding are shown in Figure 4. Before feeding, both networks operate over a wide range of periods, with gastric periods lasting from 20 to $100 \mathrm{sec}$ (Fig. 4 $A_{1}$ ), and pyloric periods from 1.6 to $5 \mathrm{sec}$ (Fig. $4 B_{1}$ ). As already explained in Clemens et al. (1998), gastric periods $>100 \mathrm{sec}$ were considered to be pauses in gastric network activity. Gastric activity expresses a unimodal distribution, with the most frequently occurring periods in the range of $20-40 \mathrm{sec}$. In contrast, the pyloric circuit expresses a bimodal pattern with two distinct modes of activity. These two modes correspond to the pyloric cycles occurring between cycles involving the gastric interaction (mode at 2.2-2.8 sec) and those influenced by the gastropyloric interaction (mode at 3.8-4.6 sec) (Clemens et al., 1998). After feeding, both the gastric and the pyloric distributions shift to lower mean period lengths, with gastric periods varying from 10 to $20 \mathrm{sec}$ with no pauses (Fig. $4 A_{2}$ ), whereas pyloric periods now mostly range from 1.2-1.8 sec (Fig. $4 B_{2}$ ). Moreover, the typical bimodal distribution pattern of the pyloric period that is associated with the gastropyloric interaction before feeding disappears after feeding, and consequently pyloric period now displays a unimodal distribution.

\section{Feeding-related changes in stomatogastric network expression are accompanied by changes in arterial $\mathrm{Po}_{2}$}

Because low arterial $\mathrm{Po}_{2}$ appears to be a limiting factor in the expression of rapid pyloric rhythmicity in vitro and oxygen was proposed to play a neuromodulator-like role in the function of the stomatogastric system (Massabuau and Meyrand, 1996), we wished to assess whether changes in arterial $\mathrm{PO}_{2}$ are involved in the changes in network activity seen after feeding behavior. In a first step therefore, we measured arterial blood $\mathrm{Po}_{2}$ changes of animals during the time course of pre- and postprandial behavior. Figure 5 shows measurements of arterial $\mathrm{PO}_{2}$ (filled squares, solid line) in parallel with the time course of the pyloric cycle period after feeding (open circles, dashed line), as already presented in Figure $2 B$. Interestingly, the reduction in pyloric period after feeding is a mirror image of the increase in mean arterial $\mathrm{PO}_{2}$. 


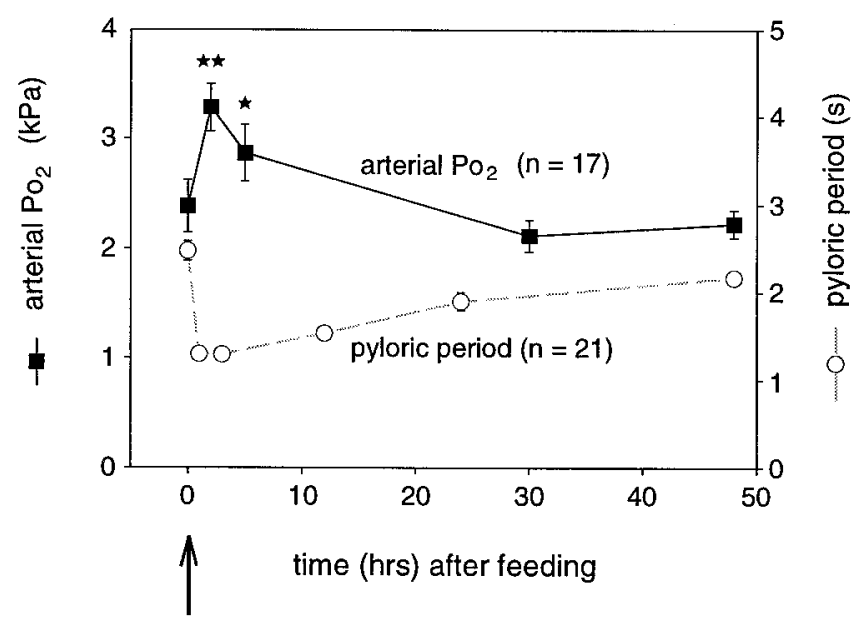

Figure 5. Time course of mean arterial $\mathrm{PO}_{2}$ after feeding (filled squares, solid line). For comparison, the postprandial time course of pyloric period after feeding, as shown in Figure $2 B$, is also plotted (open circles, dashed line). After feeding, as pyloric period decreases, arterial $\mathrm{PO}_{2}$ increases significantly and then both parameters return gradually toward control values. ${ }^{* *} p<0.01 ;{ }^{*} p<0.05$; Mann-Whitney test.

Consistent with the conclusions of Massabuau and Meyrand (1996), this parallel evolution was the first indication that oxygen changes might play an active role in shaping motor expression after feeding and that preprandial low arterial $\mathrm{PO}_{2}$ indeed limits the expression of fast pyloric rhythmicity in vivo.

\section{Prevention of postprandial $\mathrm{Po}_{2}$ augmentation restores prefeeding pyloric pattern}

In a next step toward determining whether the observed changes in pyloric frequency after feeding were causally linked to the augmentation of oxygen partial pressure in the blood, we examined the effects of a temporary hypoxia in vivo by transiently suppressing the increase in arterial $\mathrm{PO}_{2}$ after feeding. Histograms in Figure 6 represent measurements of arterial $\mathrm{PO}_{2}$ in 17 animals before feeding (Fig. 6A) and after feeding under normoxic (Fig. $6 B_{1}, B_{3}$ ) and transiently hypoxic (Fig. $6 B_{2}$ ) experimental conditions. The in vivo EMG recordings illustrate the typical motor expression of pyloric and gastric networks in a single animal under each of these conditions. Figure $6 \mathrm{~A}$ shows that before feeding, the arterial $\mathrm{PO}_{2}$ of unfed and acclimated animals lies within the range of $1-6 \mathrm{kPa}$, with most frequently measured values between 1 and $2 \mathrm{kPa}$. Under these conditions of blood oxygenation, the pyloric and gastric networks perform continuously, albeit relatively slowly (right panel). Moreover, the pyloric PY neurons express a gastric MG neuron-timed (underlined) prolongation in each cycle (see arrows). After feeding (Fig. $6 B_{1}$, control), arterial $\mathrm{Po}_{2}$ displays a mode at 2-4 $\mathrm{kPa}$ and no value beneath $2 \mathrm{kPa}$. At the same time, the pyloric and gastric networks oscillate more rapidly, and their functional interaction disappears. Note that the recordings in Figure $6 B_{1}$ once again highlight the typical effects of feeding on the motor output of pyloric and gastric networks: (1) acceleration of pyloric and gastric cycling, (2) loss of the interaction between the two networks, and (3) an increase in the duty cycle of the MG neuron and a corresponding decrease for LPG.

Experimental lowering of arterial $\mathrm{PO}_{2}$ in fed animals down to prefeeding modal levels 1-3 hr after feeding (see Materials and Methods) has two effects on the stomatogastric motor pattern (Fig. $6 B_{2}$ ). First, pyloric cycle periods become longer (here $1.7 \mathrm{sec}$ instead of $1.2 \mathrm{sec}$ ), and second, this manipulation reestablishes the gastropyloric interaction seen before feeding (arrows in right panel). Significantly, moreover, gastric mill activity did not appear to be affected by the transient hypoxia in that no change in gastric rhythm frequency or phase relationship between the different muscles was observed. The effects of this manipulation, which were completely reversible (Fig. $6 B_{3}$ ), were seen in all such EMG experiments performed $(n=5)$. Thus, forcing postprandial animals into a temporary hypoxia restores several, but not all, features of pyloric and gastric network activity seen before feeding. This indicates that changes in oxygen levels within the physiological range indeed are able to specifically influence motor network expression in vivo.

To further assess whether the observed $\mathrm{O}_{2}$-induced changes in the gastropyloric interaction were linked directly to changes in local partial pressure of oxygen directed at the neural networks themselves, we examined the effects of similar changes in oxygen level on these networks in vitro. Figure 7 shows one such experiment $(n=14)$ in which the stomatogastric ganglion only, and hence solely the pyloric and gastric networks, was exposed to changes in oxygenation of the bathing saline. In these experiments, the rostral centers of the STNS (CoG; esophageal ganglion, OG) (compare Fig. $1 A$ ) were maintained under standard saline equilibrated at $\mathrm{PO}_{2}$ $=20 \mathrm{kPa}$ (see Materials and Methods). Moreover, to distinguish $\mathrm{PO}_{2}$ effects on pyloric frequency from those on the gastropyloric interaction, we chose to work in the $2.5-5.0 \mathrm{kPa}$ range of $\mathrm{PO}_{2}$ values, at which no significant effect on pyloric cycle frequency has been reported (Massabuau and Meyrand, 1996).

When the STG in vitro is superfused with saline equilibrated at $2.5 \mathrm{kPa}$, the gastropyloric interaction is still evident in the spontaneous activity patterns of the two networks. This coupling is again characterized by a prolongation of a single PY burst (Fig. 7, arrows) after the onset of each gastric $\mathrm{MG}$ neuron burst (Fig. $7 A$ ). In contrast, when $\mathrm{Po}_{2}$ is increased to $5 \mathrm{kPa}$, a value representing the situation in the animal after feeding, this functional interaction disappears (Fig. 7B), although both pyloric and gastric cycle periods remain unchanged. This local effect of oxygen, which is completely reversible (Fig. $7 C$ ), demonstrates therefore that oxygen directly influences the expression of the gastropyloric relationship at the STG level itself.

It is also noteworthy that in these in vitro experiments, as in vivo, both gastric period length and phase relationships between the gastric muscles evidently were not affected by the $\mathrm{PO}_{2}$ changes. Indeed, as illustrated in Figure 8, which shows data from four experiments, the spontaneously oscillating pyloric and gastric networks react differently to low levels of oxygen. At $\mathrm{PO}_{2}$ of $1-3 \mathrm{kPa}$, corresponding to values observed in prefeeding animals, pyloric cycle frequency lies between 0.5 and $0.8 \mathrm{~Hz}$ (period of $2.0-1.25 \mathrm{sec}$ ), whereas at $\mathrm{Po}_{2}$ of $3-20 \mathrm{kPa}$ the frequency ranges from 0.8 to $1.0 \mathrm{~Hz}$ (period $1.25-1.0 \mathrm{sec}$ ). In contrast, over this same $\mathrm{PO}_{2}$ range, no significant difference in the rate $(0.15 \mathrm{~Hz}$, period $\sim 7 \mathrm{sec}$ ) of gastric cycling is observed.

This indicates that $\mathrm{PO}_{2}$ differentially influences stomatogastric network activity, in that compared with the pyloric network, gastric rhythmogenesis appears to be relatively insensitive to different states of local oxygenation.

\section{DISCUSSION}

In this study we present evidence that (1) a feeding stimulus conjointly modulates the gastric and pyloric motor patterns of the stomatogastric nervous system, (2) this long-lasting modulation involves a parallel acceleration of both networks and a loss of a 


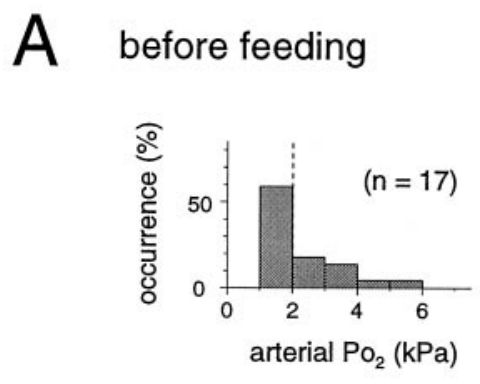

$\mathrm{B}_{1}$ after feeding $\mathrm{B}_{2}$

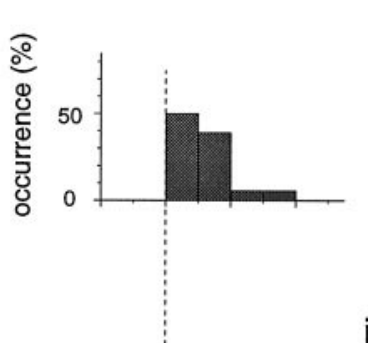

\section{imposed lowered arterial $\mathrm{PO}_{2}$}

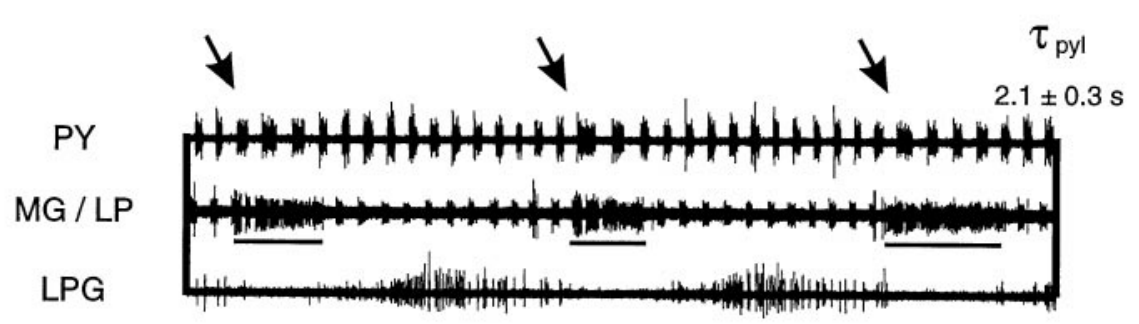

control
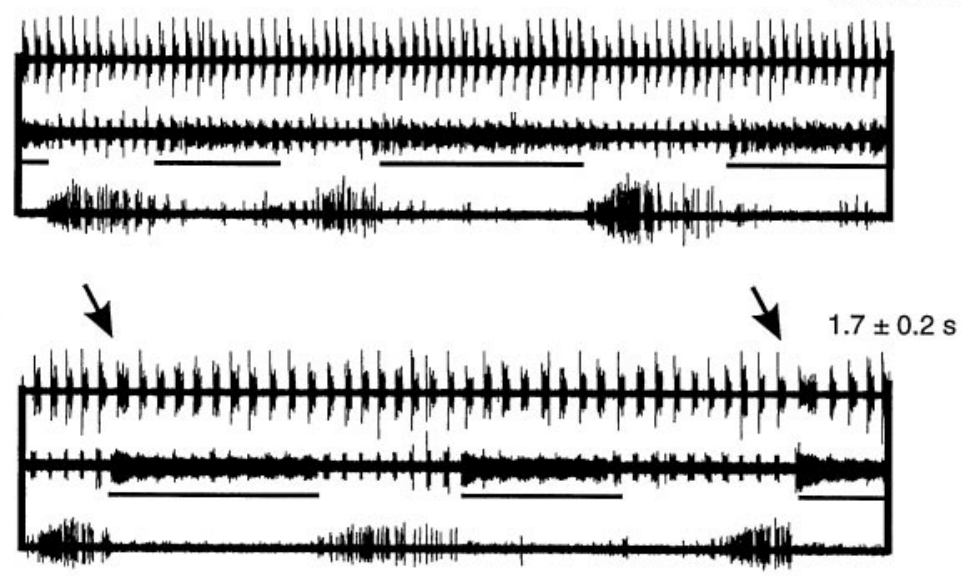

recovery

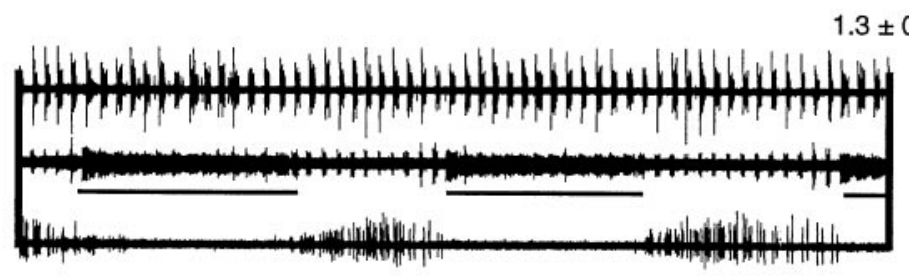

$10 \mathrm{~s}$

Figure 6. Transient hypoxia partially reverses postprandial changes in vivo. A, Distribution histogram of arterial $\mathrm{PO}_{2}$ in resting unfed animals and corresponding pyloric and gastric motor patterns. $\mathrm{PO}_{2}$ lies mostly in the range of $1-2 \mathrm{kPa}$. Characteristically, cycle periods are long, and each gastric $\mathrm{MG}$ neuron burst (underlined) is associated with a pyloric network perturbation (arrows). $\tau_{\text {pyl }}$ pyloric cycle period. $B$, Effects of imposed lowered arterial Po ${ }_{2}$ after feeding. $B_{1}$, Under control conditions, after feeding, the normoxic arterial $\mathrm{PO}_{2}$ increases along with the rate of pyloric and gastric cycling, and the internetwork interaction disappears. $B_{2}$, Transient suppression of postprandial $\mathrm{PO}_{2}$ increase (by lowering water $\mathrm{PO}_{2}$ ) reverses pyloric (but not gastric) acceleration, and the internetwork interaction is restored (arrows). $B_{3}$, These effects are reversible.

coordinating interaction between them, and (3) these feedingrelated changes occur concomitantly with an increase in arterial partial pressure of oxygen. Importantly, experimental manipulation of oxygen bathing the stomatogastric ganglion in vivo can reverse the postprandial increase in pyloric cycle frequency as well as the expression of the gastropyloric interaction. Moreover, both of these $\mathrm{PO}_{2}$-dependent changes can be reproduced in vitro. Consequently, we propose that in lobster, changes in physiological levels of arterial $\mathrm{Po}_{2}$, acting specifically at the level of the stomatogastric ganglion, contribute to the multiple network modulation necessary for feeding-related behavior.

\section{Feeding causes long-lasting enhancement of pyloric and gastric network performance}

Although several studies have reported the effects of feeding behavior on the motor expression of crustacean pyloric (Rezer and Moulins, 1983, 1992) and gastric networks (Fleischer, 1981; Turrigiano and Selverston, 1990) separately, the present work is the first report on the conjoint long-term modulation of pyloric and gastric activity after feeding (Figs. $2 A, 3,4$ ). Our finding that feeding accelerates both pyloric and gastric network activity in $H$. gammarus for $24-48 \mathrm{hr}$ (Fig. 2B,C) is consistent with previous data from Panulirus interruptus (Fleischer, 1981; Turrigiano and Selverston, 1990) and Jasus lalandii (Hill, 1976) (S. Mayfield, personal communication), although Barker and Gibson (1977) reported that in $H$. gammarus the complete digestive cycle in terms of hepatopancreatic activity does not last beyond $12 \mathrm{hr}$.

Several studies have reported that in crustaceans, several peaks of postprandial digestive activity may be observed, with a main peak occurring in the first 3-5 hr after feeding (Vonk, 1960; Barker and Gibson, 1977). In this context it is interesting that 


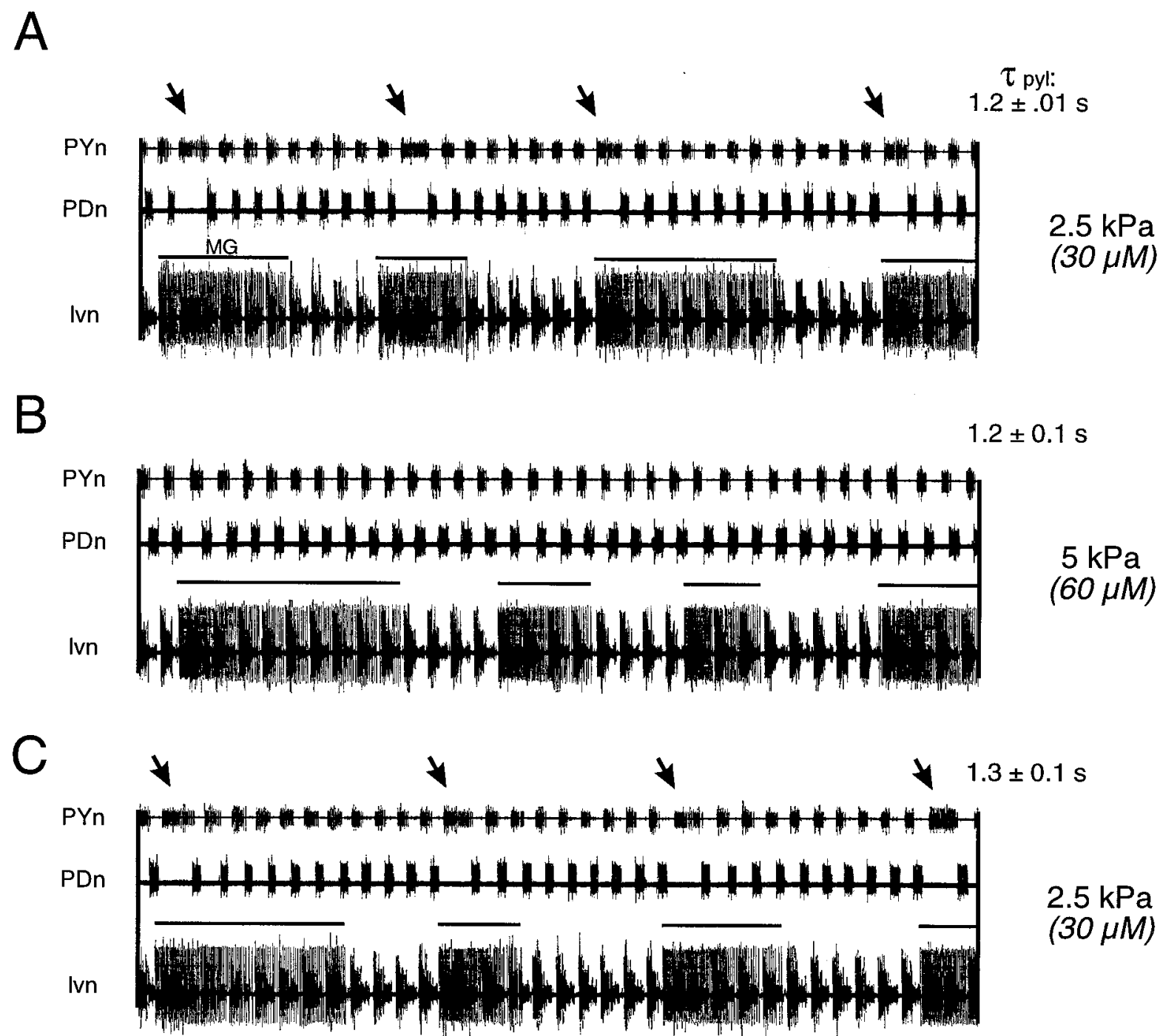

\begin{abstract}
$10 \mathrm{~s}$
Figure 7. Selective action of $\mathrm{PO}_{2}$ on gastropyloric interaction in vitro. $A$, During superfusion of the $\mathrm{STG}$ alone with equilibrated saline at $\mathrm{Po}_{2}=2.5 \mathrm{kPa}$, the spontaneously active gastric and pyloric networks express an interaction (arrows) similar to that seen in resting and unfed animals. Each onset of a gastric MG neuron burst (solid line above lvn trace) is followed by a single perturbation in the pyloric network cycle. $B$, Superfusing the STG with saline oxygenated at $5 \mathrm{kPa}$ leads to a disappearance of the internetwork interaction, without affecting pyloric or gastric cycle frequency in this $\mathrm{PO}_{2}$ range. $C$, This specific action is reversed on return to control conditions. $\tau_{\text {pyl }}$, Pyloric cycle period.
\end{abstract}

Turrigiano and Selverston (1989, 1990) have shown that the acceleration of gastric network activity after food intake is causally related to a short-lasting $(<3 \mathrm{hr})$ peak of a cholecystokinin (CCK)-like hormone in the hemolymph of $P$. interruptus. That the release of this peptide hormone is raised only transiently after feeding indicates that multiple modulatory processes with different time courses of action are responsible for the full range of modifications (lasting up to $48 \mathrm{hr}$ ), such as those reported in the present study.

Apart from modifications in cycle frequency and gastropyloric coordination, other feeding-related changes in network activity were not obvious in our in vivo experiments. This was somewhat surprising given the extent to which both the gastric and pyloric networks in vitro are known to be capable of operational flexibility under extrinsic modulatory instruction (Dickinson and Nagy, 1983; Nagy and Dickinson, 1983; Cazalets et al., 1990; Meyrand

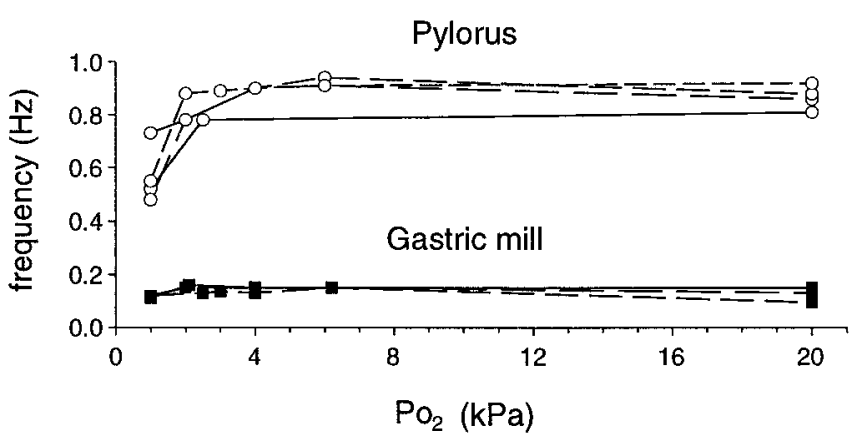

Figure 8. Differential effects of $\mathrm{PO}_{2}$ on pyloric and gastric networks in vitro. Pyloric activity is considerably influenced by different oxygenation levels only in the physiological range of $1-3 \mathrm{kPa}$. By contrast, gastric cycling remains unaffected ( $n=4$ preparations). 
et al., 1991, 1994; Harris-Warrick et al., 1992). Two alternative, but not necessarily mutually exclusive, explanations are possible. The first possibility is that the steady-state conditions under which our in vivo experiments were performed (resting, settled animals fed with a single food type) did not call on the expression of such a large range of behavioral flexibility. Alternatively, and perhaps more significantly, our data may indicate the extent to which an assemblage of widely acting extrinsic influences on motor networks are constrained by the complete neural (central nervous and sensory information) and humoral environment of the intact animal. Thus, despite the potential for individual modulatory STG inputs to switch on and off or to sculpt distinctly different phenotypes of pyloric and gastric network activity in vitro (Harris-Warrick et al., 1992; Marder and Calabrese, 1996), in vivo the combined action of these inputs could serve more to maintain stable network operation in the face of behavioral and environmental changes (Chiel and Beer, 1997).

\section{Oxygen specifically influences pyloric rhythm frequency in vivo}

A major advantage in this study is the unique anatomical feature of crustaceans, in that the STG is located in the lumen of the ophthalmic artery without itself containing any microcirculation. Thus oxygenation of the STG networks is linked directly and intimately to levels of circulating blood oxygen, a situation that can be readily reproduced in vitro (Massabuau and Meyrand, 1996). In their study it was proposed that oxygen acts in a neuromodulator-like manner on the motor expression of the pyloric network. In brief, it was postulated that via a specific action on a single member (LP neuron) of the pyloric network, an acceleration of the entire circuit could be permitted by an increase in blood $\mathrm{PO}_{2}$. The reason for such a control process remains a matter of speculation, although a likely explanation is that oxygen could serve as a limiting factor to reduce metabolic expenditure when high work rates are not required in interprandial conditions. Our present in vivo results further strengthen this notion, suggesting that low interprandial $\mathrm{PO}_{2}$ indeed serves as a constraining factor for network function. In contrast to the pronounced effect of low $\mathrm{PO}_{2}$ on the pyloric rhythm, we did not observe any significant oxygen effect on the gastric rhythm (Fig. 8). This may reflect a state-dependent action proposed previously by Massabuau and Meyrand (1996), who showed that the effect of oxygen on a slowly oscillating pyloric network is weak or even absent. Presumably therefore, some other modulatory factor(s) is responsible for the acceleration of gastric network rhythmicity after feeding.

\section{Feeding influences the expression of gastropyloric interaction}

Concomitant with the frequency changes in pyloric and gastric networks after feeding is a sudden disappearance of the gastropyloric interaction, which then recovers progressively over the ensuing days (Fig. 3). The loss of this functional interaction, for which the synaptic pathway was described recently for H. gammarus (Clemens et al., 1998), thereby allows the two networks to operate largely independently of each other after feeding.

The switch from coordinated to completely independent modes of activity associated with feeding could underlie a change between different functional tasks. For example, the coordinated action of gastropyloric circuits in unfed animals (Fig. 9A) could serve to mix and draw digestive enzymes synthesized in the hepatopancreas (Vonk, 1960; Conklin, 1980) forward into the
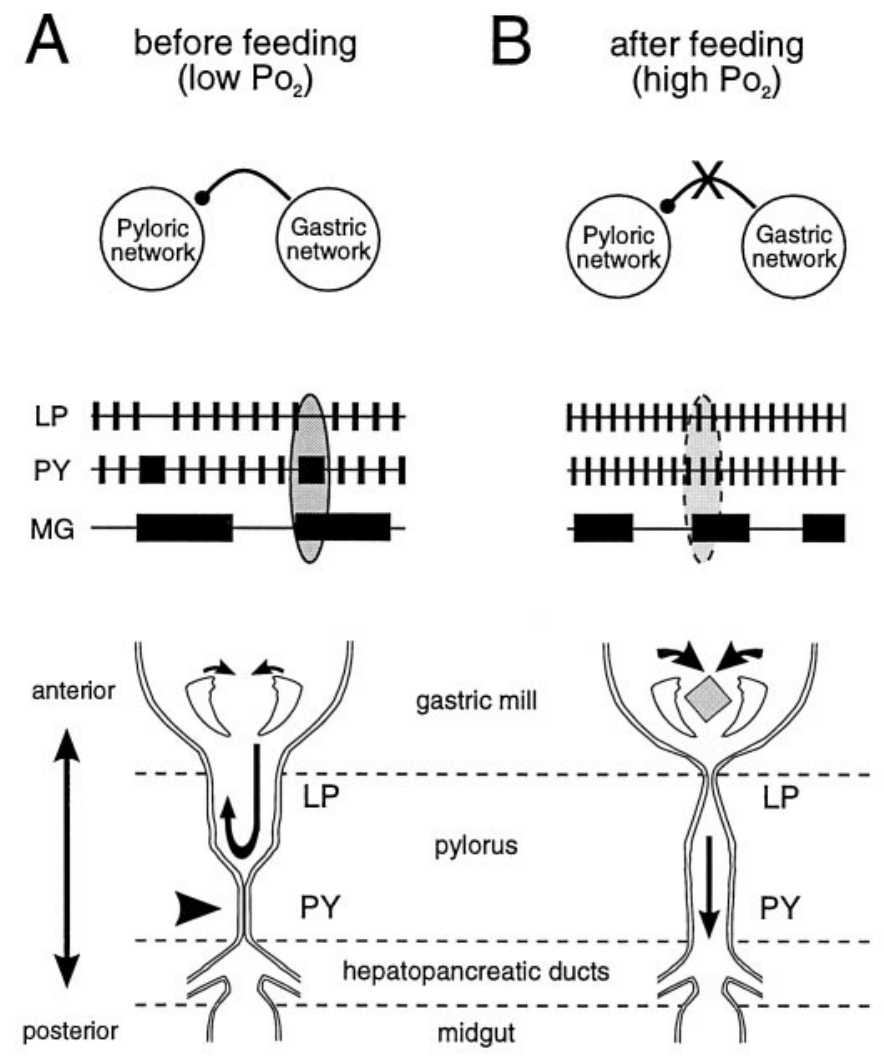

\section{Coordinated interaction}

No interaction

Figure 9. Model of proposed changes in foregut function before and after feeding. $A$, Before feeding, at low $\mathrm{PO}_{2}$, the gastric and pyloric networks cycle slowly and express an interaction in which PY and MG neuron bursts are coordinated. During the sustained contraction of the posterior part of the pylorus attributable to a longer-lasting drive from the PY neurons, the anterior region (controlled by the LP neuron) will remain open. This may allow a pumping action of the gastric teeth to transfer digestive enzymes, present in the pylorus, toward the stomach and esophagus. $B$, After feeding, at higher $\mathrm{PO}_{2}$, the two networks now perform their separate behavioral tasks (masticatory function of the gastric mill and filtering function of the pylorus) without a coordinating interaction. Note that the switch from one functional state to the other is under the control of local $\mathrm{PO}_{2}$ changes at the STG level.

anterior foregut. After feeding, however, the uncoupling of these networks would allow separate functional roles in the regional processing of ingested food (Fig. 9B).

Coordinating interactions between different networks have been described in various systems, and their modulation as a function of behavioral changes has been reported (Funk et al., 1989; Young et al., 1992; Bernasconi and Kohl, 1993). In most cases, however, neither the synaptic pathways for coordination nor their modulatory influences are known (Dickinson, 1995). In the model we study, the communicating synaptic pathway between the gastric and pyloric networks has been elucidated (Clemens et al., 1998), and the present study now proposes a novel means by which this intercircuit pathway can be modulated.

\section{The gastropyloric interaction is modulated by oxygen}

In unfed animals with low blood $\mathrm{Po}_{2}$, the onset of each gastric $\mathrm{MG} / \mathrm{LG}$ neuron burst is followed by a significant prolongation of PY neuron bursts (Figs. $1 C, 2 A$ ). As shown previously, this 
intercircuit coupling is mediated by an inhibitory synapse between $\mathrm{MG} / \mathrm{LG}$ neurons and the pacemaker $\mathrm{PD} / \mathrm{AB}$ neurons of the pyloric network (Fig. 1B) (Clemens et al., 1998). After feeding, when blood $\mathrm{PO}_{2}$ is augmented and both networks are oscillating more rapidly, this interaction disappears (Figs. $\left.2 A, 6 B_{1}\right)$.

One possibility is that the gastropyloric interaction depends strictly on the frequency of pyloric cycling, appearing only at times when this network is oscillating relatively slowly. However, our in vitro experiments, in which the interaction could be clearly modulated in a $\mathrm{Po}_{2}$ range in which an alteration in pyloric frequency is weak or absent (Fig. 7), suggested that this coupling is not merely a frequency-dependent phenomenon but is itself modulated, either directly or indirectly (such as at a presynaptic site on an extrinsic input that in turn modulates the synapse), by arterial $\mathrm{PO}_{2}$. That this regulation is targeted functionally at the connection between the two networks is further attested by the fact that in these experiments changes in $\mathrm{PO}_{2}$ were imposed at the level of the STG only, with the rostral ganglia maintained under constant ambient conditions. Therefore, although we do not know whether the change in coupling efficacy occurs at presynaptic or postsynaptic sites or both, our data show that oxygen at physiological levels is able to modulate synaptic communication between two distinct, but behavioral-related, neural networks.

\section{Conclusions}

It is now established that various neuromodulatory influences can modify the expression of a neural network by regulating both cellular properties of individual neurons and their synaptic connections (Marder and Calabrese, 1996). Moreover, in recent years evidence has accumulated for a modulatory role of gaseous substances such as nitric oxide (Bredt et al., 1990; Bredt and Snyder, 1992; Pape and Mager, 1992; Moroz et al., 1993) and carbon monoxide (Zhuo et al., 1993) also acting on neuronal membrane and synaptic properties.

Oxygen has also been shown to modulate cellular properties of neurons (Krnjevic and Leblond, 1989; Jiang and Haddad, 1994), including those of the stomatogastric circuits (Massabuau and Meyrand, 1996). However, to our knowledge, an oxygenmediated control of synaptic relationships between central neural networks has not been reported so far, although the necessarily widespread distribution and regional variability of oxygen throughout central nervous tissue makes it a likely candidate for such a role. This could be particularly relevant to the mammalian CNS, in which regional changes in cerebral blood flow associated with changes in regional network function are now known (Hofle et al., 1997).

\section{REFERENCES}

Aiken DE (1973) Proecdysis, setal development, and molt predictions in the American lobster (Homarus americanus). J Fish Res Board Can 30:1337-1344.

Barker PL, Gibson R (1977) Observations on the feeding mechanism, structure of the gut, and digestive physiology of the European lobster Homarus gammarus. J Exp Mar Biol Ecol 26:297-324.

Bernasconi P, Kohl J (1993) Analysis of co-ordination between breathing and exercise rhythms in man. J Physiol (Lond) 471:693-706.

Bredt DS, Snyder SH (1992) Nitric oxide, a novel neuronal messenger. Neuron 8:3-11.

Bredt DS, Hwang PM, Snyder SH (1990) Localization of nitric oxide synthase indicating a neural role for nitric oxide. Nature 347:768-770.

Cazalets J-R, Nagy F, Moulins M (1990) Suppressive control of the crustacean pyloric network by a pair of identified interneurons. I. Modulation of the motor pattern. J Neurosci 10:448-457.
Chiel HJ, Beer RD (1997) The brain has a body: adaptive behavior emerges from interaction of nervous system, body and environment. Trends Neurosci 20:553-557.

Clemens S, Meyrand P, Simmers J (1996) Dynamic interactions between motor pattern generating networks in the stomatogastric ganglion of intact lobster. Soc Neurosci Abstr 22:132.

Clemens S, Combes D, Meyrand P, Simmers J (1998) Long term expression of two interacting motor pattern generating networks in the stomatogastric system of freely behaving lobster. J Neurophysiol, in press.

Conklin DE (1980) Nutrition. In: The biology and management of lobsters (Cobb JS, Phillips BF, eds), Vol 1, Physiology and behavior, pp 277-300. New York: Academic.

Dickinson PS (1995) Interactions among neural networks for behavior. Curr Opin Neurobiol 5:792-798.

Dickinson PS, Nagy F (1983) Control of a central pattern generator by an identified modulatory interneurone in crustacea. II. Induction and modification of plateau properties in pyloric neurones. J Exp Biol 105:59-82.

Fleischer AG (1981) The effect of eyestalk hormones on the gastric mill in the intact lobster, Panulirus interruptus. J Comp Physiol [A] 141:363-368.

Forgue J, Massabuau J-C, Truchot J-P (1992) When are resting waterbreathers lacking $\mathrm{O}_{2}$ ? Arterial $\mathrm{Po}_{2}$ at the anaerobic threshold in the crab. Respir Physiol 88:247-256.

Funk GD, Milsom W K, Sholomenko GN, Steeves JD (1989) Role of the telencephalon in the synchronization of locomotor and respiratory frequencies during walking in Canada geese. J Exp Biol 145:283-301.

Grillner S, Deliagina T, Ekberg Ö, El Manira A, Hill RH, Lansner A, Orlovsky GN, Wallén P (1995) Neural networks that coordinate locomotion and body orientation in lamprey. Trends Neurosci 18:270-279.

Harris-Warrick RM, Marder E, Selverston AI, Moulins M (1992) Dynamic biological networks: the stomatogastric nervous system. Cambridge, MA: MIT.

Heinzel HG, Weimann JW, Marder E (1993) The behavioral repertoire of the gastric mill in the crab Cancer pagurus: an in situ endoscopic and electrophysiological examination. J Neurosci 13:1793-1803.

Hill BJ (1976) Natural food, foregut clearance-rate and activity of the crab Scylla serrata. Marine Biol 34:109-116.

Hofle N, Paus T, Reutens D, Fiset P, Gotman J, Evans AC, Jones BE (1997) Regional cerebral blood flow changes as a function of delta and spindle activity during wave sleep in humans. J Neurosci 17:4800-4809.

Jiang C, Haddad GG (1994) A direct mechanism for sensing low oxygen levels by central neurons. Proc Natl Acad Sci USA 91:7198-7201.

Kaczmarek LK, Levitan IB (1987) Neuromodulation: the biochemical control of neuronal excitability. New York: Oxford UP.

Katz PS (1995) Intrinsic and extrinsic neuromodulation of motor circuits. Curr Opin Neurobiol 5:799-807.

Katz PS, Frost WN (1995a) Intrinsic neuromodulation in the Tritonia swim CPG: the serotonergic dorsal swim interneurons act presynaptically to enhance transmitter release from interneuron C2. J Neurosci 15:6035-6045.

Katz PS, Frost WN (1995b) Intrinsic neuromodulation in the Tritonia swim CPG: serotonin mediates both neuromodulation and neurotransmission by the dorsal swim interneurons. J Neurophysiol 74:2281-2294.

Krnjevic K, Leblond J (1989) Changes in membrane currents of hippocampal neurons by brief anoxia. J Neurophysiol 62:15-30.

Marder E, Calabrese RL (1996) Principles of rhythmic motor pattern generation. Physiol Rev 76:687-717.

Massabuau J-C, Forgue J (1996) A field vs laboratory study of blood $\mathrm{O}_{2}$-status in normoxic crabs at different temperatures. Can J Zool 74:423-430.

Massabuau J-C, Meyrand P (1996) Modulation of a neural network by physiological levels of oxygen in lobster stomatogastric ganglion. J Neurosci 16:3950-3959.

McCormick DA, Bal T (1994) Sensory gating mechanisms of the thalamus. Curr Opin Neurobiol 4:550-556.

McMahon, Wilkens JL (1975) Respiratory and circulatory responses to hypoxia in the lobster Homarus americanus. J Exp Biol 62:637-655.

Meyrand P, Simmers J, Moulins M (1991) Construction of a pattern- 
generating circuit with neurons of different networks. Nature 351:60-63.

Meyrand P, Simmers J, Moulins M (1994) Dynamic construction of a neural network from multiple pattern generators in the lobster stomatogastric nervous system. J Neurosci 14:630-644.

Moroz LL, Park J-H, Winlow W (1993) Nitric oxide activates buccal motor patterns in Lymnaea stagnalis. NeuroReport 4:643-646.

Nagy F, Dickinson PS (1983) Control of a central pattern generator by an identified modulatory interneurone in crustacea. I. Modulation of the pyloric motor circuit. J Exp Biol 105:33-58.

Pape H-C, Mager R (1992) Nitric oxide controls oscillatory activity in thalamocortical neurons. Neuron 9:441-447.

Rahn H (1966) Aquatic gas exchanges: theory. Respir Physiol 1:1-12.

Rezer E, Moulins M (1983) Expression of the crustacean pyloric pattern generator in the intact animal. J Comp Physiol [A] 153:17-28.

Rezer E, Moulins M (1992) Humoral induction of pyloric rhythmic output in lobster stomatogastric ganglion: in vivo and in vitro studies. $\mathrm{J}$ Exp Biol 163:209-230.
Selverston AI, Moulins M (1987) The crustacean stomatogastric system. Berlin: Springer.

Steriade M, McCormick DA, Sejnowski TJ (1993) Thalamocortical oscillations in the sleeping and aroused brain. Science 262:679-685.

Turrigiano GG, Selverston AI (1989) Cholecystokinin-like peptide is a modulator of a crustacean central pattern generator. J Neurosci 9:2486-2501.

Turrigiano GG, Selverston AI (1990) A cholecystokinin-like hormone activates a feeding-related neural circuit in lobster. Nature 344:866-868.

Vonk HJ (1960) Digestion and metabolism. In: Physiology of crustacea, Vol 1 (Waterman TH, ed), pp 291-316. New York: Academic.

Young IS, Alexander RMcN, Woakes AJ, Butler PJ, Anderson L (1992) The synchronization of ventilation and locomotion in horses (Equus caballus). J Exp Biol 166:19-31.

Zhuo M, Small SA, Kandel ER, Hawkins RD (1993) Nitric oxide and carbon monoxide produce activity-dependent long-term synaptic enhancement in hippocampus. Science 260:1946-1950. 